\title{
Ethical Leadership as an Influence: A Multi-Level Analysis Predicting Citizenship Behavior
}

\author{
Maheen Masood \\ Department of Business Administration \\ Lahore School of Economics
}

\begin{abstract}
This study incorporates two different types of perspectives determining the factors influencing citizenship behavior. Social exchange perspective incorporates the interpersonal relations of leaders and followers, which are hamper through workplace ostracism. Social learning perspective considers an employee's behavior to be influence by the ethical behavior of their leader. In order to study the impact of these diverse views on citizenship behavior, a multilevel model of ethical leadership is develop in order to determine the direct, indirect and cascading effects of workplace ostracism on either organizational or compulsive citizenship behavior. The study proposed that immediate level managers ethical leadership practices tend to have the greatest impact on the citizenship behavior of employees. In addition, if the immediate level manager adopts an ostracized behavior with its subordinates then it will lead to compulsive citizenship behavior. Besides this, higher-level manager's ethical leadership practices also play a vital role in influencing citizenship behavior unlike lower level managers who have the least influential impact on middle level employees.
\end{abstract}

Keywords: Citizenship Behavior, Workplace Ostracism, Ethical Leadership

\section{Introduction}

Over the last three decades, organizational scholars have extensively researched on the antecedents and consequences of predicting an employee's behavior (Podaskoff et al. 2000; Zhao et al, 2014). An employee behavior has been a focus of concern for practitioners and scholars because it is relatively difficult to predict, determine and measure behavior. Prior research has studied citizenship behavior as a multi-dimensional construct which has its positive outcomes in terms of organizational citizenship behavior (LePine, Erez, \& Johnson, 2002; Luthans\& Youssef, 2007; Podsakoff et al., 2009) and negative outcomes in terms of compulsory citizenship behavior (Vigoda-Gadot, 2007; Zhao et al., 2014; Alkan \& Turgut, 2015). The prevalent literature has clearly made distinctions between these two constructs based on the former being a voluntary helping behavior, and the latter being a forced involuntary behavioral outcome (Ahmad \& Khan, 2016; Vigoda-Gadot, 2007). Prior studies have also emphasized on the role of ethical leadership and ostracized behavior as being pivotal in determining organizational citizenship behavior (Yang \& Wei, 2018). On one hand, ethical leadership tends to emphasize on the ethical code of conduct that influences organizational citizenship behavior; whereas, on the other hand ostracized behavior of managers are study in terms of the negative impact it has on an employee's behavior and performance. (Mayer et al. 2012; Schaubroeck et al. 2012).

While the existing research has advanced our knowledge regarding the types of citizenship behavior, certain gaps in the prior research are identify in terms of inadequate problematizing of the literature. The role of ethical leadership and ostracized behavior in influencing citizenship behavior needs to be examined (Liu \& Xia, 2016). Moreover, the role of a distal and proximal leader in determining the influence on citizenship behavior is not analyze before highlighting the need to conduct a multi-level analysis of the managerial positions predicting behavior. In addition, workplace ostracism is a growing phenomenon, which requires more attention due to the increasing trend of ostracized behavior amongst different managerial levels prevalent within an organization.

My intent here is to increase the understanding of individual level citizenship behavior through proposing a multi-level model of ethical leadership and workplace ostracism and its impact on behavior. To accomplish this aim, two different perspectives of citizenship behavior are analyze comprising of social exchange perspective and social learning perspective. Social exchange perspective highlights the relevance of workplace ostracism in playing a vital role in determining behaviour whereas; social learning perspective gives rise to the importance of ethical leadership in influencing behavior. It is important to address these limitations because measuring behavior has always been a challenge for organizational members. Existing studies have directed the mangers towards pressurizing the employees to behave in a certain manner. However, it is necessary to view the other perspective of enhancing behavior through not only personal factors but instead managerial level factors as well. Therefore, the present study aims at accomplishing two goals. 
Firstly, to analyze the two perspectives that influences citizenship behavior comprising of social exchange perspective and social learning perspective. Secondly, propose a multi-level model to determine the impact of higher, lower and immediate level ethical leaders on individual level citizenship behavior through an intervention of workplace ostracism.

The research questions are interesting and important to address because the distinction between two integral theories of psychology will provide the scholars and practitioners with distinct perspective of analyzing citizenship behavior of employees. In addition, a hierarchical level analysis of ethical leadership and ostracized behavior of managers have been a relatively neglected area in organizational studies, which provides major insights regarding behavior of employees.

The significance of the study is that it highlights the importance of organizational citizenship behavior, which entails the extent to which an employee goes beyond his/her job description. The study validates the relationship between the variables under Pakistani context due to the following reasons. Firstly, addressing the unethical concerns has been an integral area of research where the management and employees are not accountable for unethical considerations. Secondly, it is necessary to highlight the factors that lead to either organizational or compulsory citizenship behavior of employees. This will enable the managers to identify the loopholes prevalent within an organizational culture that might be negatively influencing behavioral outcomes. Thirdly, the ostracized behavioral influence on the subordinates by the immediate level managers or high/lower level managers will determine the relevance and cascading effects of ethical leadership prevalent within an organization.

Lastly, the study aims at delivering certain learning outcomes of behavior existing within an organization. It will give a different perspective to the scholars and organizational members towards citizenship behavior. This perspective will incorporate the managerial level determinants of citizenship behavior such as ethical leadership and ostracized behavior. The comparison of these theories will generate interesting insights regarding the factors influencing citizenship behavior through a mediating role of workplace ostracism.

\section{Theoretical Development}

Research on the practices of unethical leadership within an organization has been a focus of concern for the internal stakeholders, along with other behavioral considerations, which influence an employee's citizenship behavior. The research model presented in this article draws attention to explain how leaders at different levels take into account ethical considerations, which furthermore leaves an impact on an employee's citizenship behavior. An ethical leader will have appropriate behavior through interpersonal and interactional relationships that will encourage employees to promote an effective behavior within the organization (Brown, Trevino \& Harrison, 2005).

\section{Citizenship Behaviour}

Vigoda-Gadot (2006) asserts that citizenship behavior "is considered a social structure that is highly dependent upon innovative and spontaneous activities that are beyond the prescribed role requirements." The element of extra work requirement gives rise to the concept of "organizational citizenship behavior." According to Organ (1988), an organizational citizenship behavior "is discretionary, not directly or explicitly recognized by the formal reward system, and that in the aggregate promotes the effective functioning of the organization." A lot of empirical research is conduct in testing the constructive impact of organizational citizenship behavior on an employee's performance and organizational effectiveness (Bolino et al. 2010; Podsakoff et al. 2000). However, Vigoda Gadot (2006) came up with a distinct view of citizenship behavior. In this case, employees might not be willing to perform organizational citizenship behavior because they are not rewarded. Therefore, Vigoda-Gadot (2006) proposed that when citizenship behavior loses its voluntary perspective and is affect by external pressures then it leads towards "compulsive citizenship behavior." It is define as "an involuntary behavior which is not a self-driven goodwill of the employees (VigodaGadot, 2007). The differentiating link between OCB and CCB is clearly define through the level of spontaneity, extra role activities based on employee's will and a dynamic rather than a voluntary behavior (Bolino et al. 2010; Fox et al. 2012).

\section{Dimensions of Citizenship Behaviour}

Organizational citizenship behavior is a widely studied construct; whereas, compulsory citizenship behavior requires more light to be shed upon. Due to this reason, organizational citizenship behavior has a developed scale of measures, which are popularly use by scholars (Organ, 1988; George \& Brief, 1992; Lim \& Loosemore, 2017; Chan \& Lai, 2017). These measures include altruism, conscientiousness, sportsmanship, courtesy and civic virtue. However, the measures of compulsory citizenship behavior are identifed by Vigoda-Gadot (2006) comprising of a 5-item scale. Therefore, this study makes a comparison between the measures of organizational citizenship behavior and compulsory citizenship behavior in order to provide a collective view of citizenship behavior. 
Altruism includes discretionary behaviors that are required for helping others with an organizationally relevant task or problem (Organ, 1988). From an OCB perspective, willingly helping co-workers will comprise of altruism; whereas, from CCB perspective it is a forced dynamic behavior to help others beyond an employee's formal obligations and even when they are short on time and energy.

Civic Virtue includes a behavior that is responsibly participating in the political life of the organization (Organ, 1988). OCB is based on gestures such as attending meetings, replying to emails or discussing issues of colleagues during personal time. On the other hand, CCB will entail a pressure from the management to engage in extra role work activities, which are beyond their formal job tasks.

Conscientiousness is when the employees of an organization carry out certain role requirements, which are not a part of their job-description (Organ, 1988). From an OCB perspective, the willingness to perform the role requirement and not considering it as an extra role requirement comprises of conscientiousness. Whereas, CCB will enforce you to think that you are expect to invest more effort in the job that is way beyond your willingness and job requirements.

Sportsmanship is a behavior that avoids complaining or aggravating unpleasant situations such as avoiding petty grievances (Organ, 1988). OCB will require emphasis on the functional behavior of an employee; whereas, CCB might take into account the dysfunctional behavior such as complaining about the social pressure in the organization to work for extra hours without any formal recognition and reward.

Courtesy is a behavior that prevents problems from occurring, as you get involved with those parties whose work will be affect by ones decisions or commitments (Organ, 1988). OCB will require voluntarily trying to ensure that problem solving takes place effectively and efficiently within the organization such as giving advance notices, passing important information or consulting/briefing. On the other hand, CCB will allow employees to consider that they are force to assist the supervisor against their will and beyond their job obligations.

\section{Different perspectives on Citizenship Behavior}

The impact of ethical leadership levels on citizenship behavior can be study from two different perspectives. The influence of workplace ostracism on citizenship behavior supports the social exchange theory. Whereas, the ethical leaderships influence on the citizenship behavior supports the social learning theory. Table 1 summarizes the two principle line thoughts about citizenship behavior.

Social exchange theory is amongst the most influential conceptual paradigms that enable the organizations to understand their workplace behaviors. According to this theory, exchange is a subjective, relationship-oriented interaction between leaders and subordinates that is characterize by socio-emotional benefits, mutual trust and commitments (Van Dyne, Graham \&Dienesch, 1994; Chan \& Lai, 2017). Some scholars have emphasized on the positive outcomes in the form of organizational citizenship behavior (Chan \& Lai, 2017; Lim \& Loosemore, 2017) and negative outcomes in the form of compulsory citizenship behavior (Yam et al. 2017; Yildiz\&Yildiz, 2016) of interactions through a social exchange perspective. In other words, these scholars have studied the positive and negative impact of social exchange perspectives on employee's citizenship behaviors.

Prior research has emphasized on the internal and external factors that affect citizenship behavior (Vigoda-Gadot, 2007; Zhao et al. 2014; Podaskoff et al. 2000). Some of these include job stress, job loyalty, job satisfaction, commitment, task performance, participative decision-making, autonomy, burnout and politics. In my viewpoint,some other determinants influence citizenship behavior of organizational members. One of the major determinants of citizenship behavior through a social exchange perspective includes workplace ostracism (Leung et al., 2011; Yang \& Wei, 2018). Workplace ostracism is a growing universal phenomenon, which occurs across various organizational and hierarchical levels. Ferris et al. (2008) asserts workplace ostracism as "the extent to which an individual perceives that they are ignored or excluded by others in the workplace." Compared with other behaviors such as abusive supervision, uncivilized behavior or workplace bullying, workplace ostracism is more passive-aggressive relationship prevalent within the organization such as remaining silent, ignoring or not responding to greetings (Liu \& Xia, 2016).

Empirical evidence on the influence of social interactions in determining citizenship behavior has led other scholars to observe the role of leaders in influencing behavior(Mayer et al. 2012; Schaubroeck et al. 2012; Shin et al. 2015).In contrast to the social exchange theory, the social learning theory clearly demonstrates that individuals learn appropriate behaviors through observing the behavior of their leaders or role models. Based on the positions within an organization, leaders are consider legitimate models for displaying normative behaviors. These normative behaviors are given attention, emulated from credible and inspirational leaders (Mayer et al. 2009; Mayer at al. 2012).Therefore, ethical leaders will encourage ethical behaviors and try to discipline the unethical behaviors prevalent within the organization. 
In light of the social learning theory, it can be deduced that an individual behavior is not only an outcome of personal experiences but instead observational learning also leaves an impact on behavior (Brown et al. 2005; Walumbwa \&Schaubroeck 2009; Walumbwa et al. 2011). An ethical leader will behave in an ethical manner, will communicate the importance of ethics and make use of rewards and punishments to encourage ethical behaviors leading towards organizational citizenship behavior.

In contrast, leaders that engage in unethical behaviors create a negative influence on the behaviors of organizational members (Trevino \& Brown, 2005). As a result, the employees observe and are likely to imitate such inappropriate conducts. For example, if a leader is taking credit for the work done by others or lying to customers and suppliers then similar behaviors will be adopted by subordinates as well (Brown, Trevino \& Harrison, 2005; Brown \& Mitchell, 2010). If leaders are implementing unethical behaviors and are not punish for it then it will encourage compulsory citizenship behaviors within the organization.

TABLE 1. Perspectives on Citizenship Behavior: Social Exchange versus Social Learning

\begin{tabular}{clc}
\hline Characteristic & \multicolumn{1}{c}{ Social Exchange Perspective } & \multicolumn{1}{c}{ Social Learning Perspective } \\
\hline $\begin{array}{c}\text { Theoretical Justification } \\
\text { Emphasis on positive } \\
\text { behaviors }\end{array}$ & $\begin{array}{c}\text { Social exchange theory } \\
\text { Organizational citizenship behavior } \\
\text { resides in the effective interaction and } \\
\text { mutual understanding between } \\
\text { members in the absence of workplace } \\
\text { ostracism (Liu \& Xia, 2016) }\end{array}$ & $\begin{array}{l}\text { Social learning theory } \\
\text { Organizational citizenship } \\
\text { behavior will be influenced by the } \\
\text { leader's strong ethical and } \\
\text { normative behaviors prevalent } \\
\text { within the organization (Mayer et } \\
\text { al. 2012) }\end{array}$ \\
$\begin{array}{c}\text { Emphasis on negative } \\
\text { behaviors }\end{array}$ & $\begin{array}{l}\text { Compulsory citizenship behavior } \\
\text { resides in the ineffective interaction } \\
\text { and relationship conflict between } \\
\text { members in the presence of workplace } \\
\text { ostracism (Vigoda-Gadot, 2006). }\end{array}$ & $\begin{array}{l}\text { weak ethical and normative } \\
\text { behaviors prevalent within the } \\
\text { organization (Brown, Trevino \& }\end{array}$ \\
& Harrison, 2005). \\
\hline
\end{tabular}

\section{Overview of the Theoretical Framework}

In this study,a multi-level model is develop for understanding how ethical leadership and the extent of workplace ostracism positively or negatively influence an employee's citizenship behavior. Specifically, ethical leadership is examine from a hierarchical perspective comprising of higher-level managers, middle level managers and lower level managers as displayed in Figure 1. First, higher level manager's ethical leadership practices may be mirrored by that leader's follower depicting a positive downward relationship known as a "cascading effect" prevalent between different managerial levels of leadership. Second, the passage of direct and indirect effects of ethical leadership will determine the influence on individual's citizenship behaviors. Third, the mediating role of workplace ostracism will intervene the relationship between hierarchical levels of ethical leadership and individual's citizenship behavior.

Figure 1. Theoretical Model of Current Research

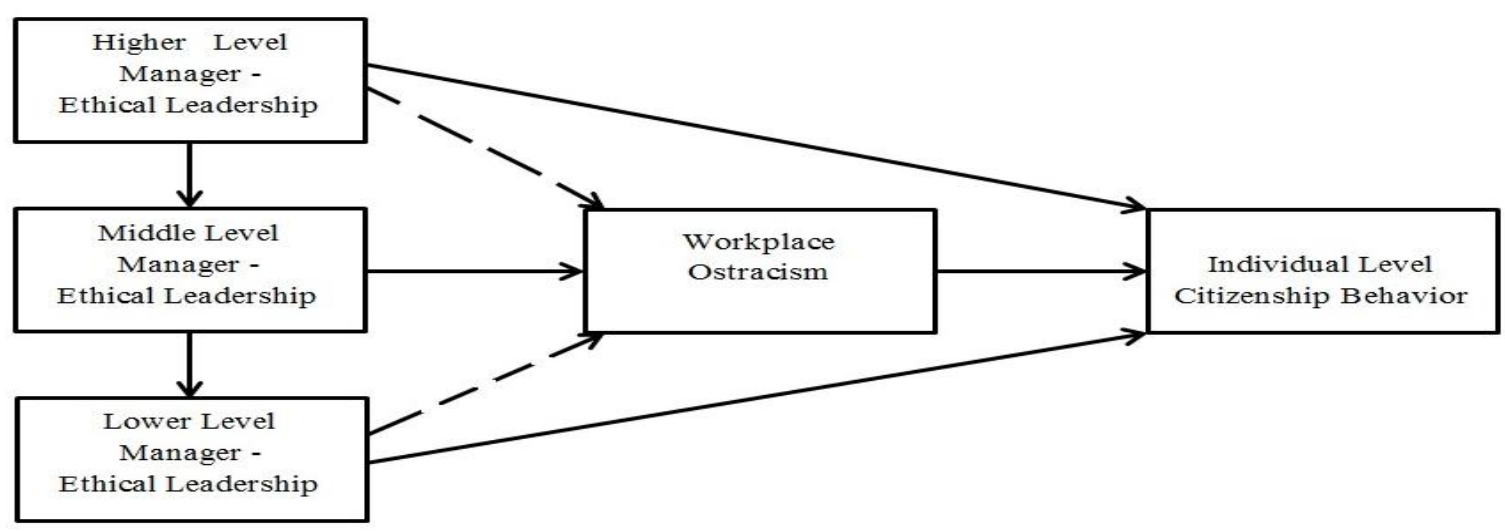




\section{Ethical Leadership}

A leader's ethical conduct plays an important role in determining efficient work conditions and employees behavior. If organizations aim at achieving sustainable growth, corporate image and strategic superiority then they have to establish a work environment that encourages ethical behavior of the leaders. Brown, Trevino and Harrison (2005) assert that ethical leadership is define as "the demonstration of normatively conduct behavior through personal actions and interpersonal relationships." These scholars identified two specific dimensions of ethical leadership; moral person and moral manager. The "moral person" dimension takes into account the personal characteristics of the leader in terms of personality traits, perceived fairness, honesty etc. If a leader possesses these characteristics then they ensure that their followers also elucidate the same ethical behavior, make appropriate choices while confronted with ethical dilemmas and communicate ethical standards within the organization. Therefore, a leader's moral personality trait gives rise to the dimension of "moral manager" which incorporates transferring the ethical behavior to the followers (Brown \& Trevino, 2006).

\section{Dimensions of Ethical Leadership}

Idealized influence is the extent to which the leader aims to become a role model for the followers by delivering high standards of ethical and moral conduct (Avolio, 1999). The delivering of high standards will explicitly incorporate the dimensions of a "moral manager" as identified by Brown and Trevino (2006). Ensuring the ability to influence the followers by conducting ethical behavior is an integral part of morality.

Interactional fairness comprises of the efforts made by a leader to treat the followers with dignity, respect and fairness of decisions (Avolio, 1999). Dignity and integrity are a part of a leaders personality traits emphasizing on the dimensions of being a "moral person" as proposed by Brown and Trevino (2006). The transfer of these components to the followers will entail ethical leadership.

Affective trustis based upon caring and the concerns of a leader for the well-being of the follower (Brown, Trevino \& Harrison, 2005). If the leader depicts from his moral behavior elements of trust and fairness only then will the follower develop the ability to have faith in the leader.

Abusive supervision comprises of the sustained display of hostile verbal and non-verbal behaviors delivered by the leaders (Tepper, 2000). These behaviors will not only depict the morality of the leader but will also influence the work outputs, performance and behavior of the followers as being victimize by these negative gestures.

\section{Transmission of Ethical Leadership through Workplace Ostracism}

The existing research on ethical leadership generally supports the idea of the influence of different hierarchical levels of management leaving an impact on the favorable outcomes and behaviors of employees prevailing at the immediate or lower levels of designations. According to the social learning theory, higher-level managers act as the most influential role model for the employees due to their power and prestige. Therefore, when higher-level managers tend to exhibit ethical conduct in leadership styles, it has the greatest impact on the employees as they try to adapt similar conduct and perform organizational citizenship behavior (Mayer et al. 2009; Shin et al. 2015).

Direct Effects of the proposed model clearly demonstrate that higher level managers ethical leadership practices tends to leave an influence on the middle level managers ethical practices (Shin et al. 2015, Mayer et al. 2009). Furthermore, middle level manager's ethical leadership practices will leave an impact on the lower level manager's ethical practices as well (Palanski, Yammarino, 2009; Brown \& Trevino, 2006). The organizational scholars (Schaubroeck et al. 2012, Brown, Trevino \& Harrison, 2005) have already established these direct effects of management influencing the ethical leadership at different levels.

However, previous leadership studies have not explicitly integrated the direct effects of higher-level managers and lower level managers ethical leadership practices on individual level citizenship behavior. According to Ehrhart and Naumann (2004) emphasized that there is a cyclical relationship prevalent between the organizational norms developed by higher levels of management and its impact on organizational citizenship behavior. These norms include descriptive norms and injunctive norms. Descriptive norms are based on the perception of employees that consider the management helpful, which in turn encourages them to perform organizational citizenship behavior. On the other hand, injunctive norms comprise of social approval or disapproval of the management by rewarding or punishing for correct or incorrect behavior. Therefore, it can be deduce that higher-level managers tend to leave a direct influence on the individual level organizational citizenship behavior (Mayer et al. 2009). In case the higher-level managers are not practicing ethical leadership and misusing their authority then it will lead towards compulsory citizenship behavior. For example, if the higher level manager does not possess a helpful behavior himself and punishes the employees for not behaving in a certain way it would encourage compulsory citizenship behavior. 
The embedding mechanism of lower level managers ethical leadership practices comprise of ensuring that the employees fulfil the organizational norms in order to achieve the desired behaviors. Lower level managers are supposed to have a relatively lesser influence on the individual level citizenship behavior of employees as they interpret moral policies/practices within the organizations less frequently and have interactive sessions with the employees on less regular basis as well in comparison to immediate level managers (Brandes, Dharwadkar\& Wheatley, 2004; Lowe, Kroeck\&Sivasubramarniam, 1996). Therefore, the lower level manager's ethical practices tends to have a less positive influence on the employee's outcomes leading towards organizational citizenship behavior and a negative influence in terms of compulsory citizenship behavior.

\section{Mediating Effects of Workplace Ostracism}

Workplace ostracism is an undermining behavior that takes into account certain directly expressed or covert behaviors (Duffy et al. 2002; Hitlan et al. 2006). When an individual experiences ostracism at workplace, they tend to develop certain psychological distress and as a precautionary measure, it prevents them from having a relatively stronger relationship with their leader (Duffy et al. 2002). According to Yang and Wei (2018) workplace ostracism will enable an employee to consider their leader as hypocrite who does not practices ethical behavior and is not consider a role model as well. Prior research has not specifically identified the impact of hierarchal management positions in determining the influence of workplace ostracism on citizenship behavior. Therefore, this study aims at contributing a different perspective towards the growing phenomena of workplace ostracism through a multi-level approach.

According to the proposed model, it can be analyze that middle level managers are most interactive personalities because they influence an individual's behavior through their own code of conduct. The presence of workplace ostracism will force an employee not to consider their leader as a "moral person" and "moral manager" due to which they will have a lack of trust for the leader and would not be willing to provide positive outcomes in the form of organizational citizenship behavior. Instead, incidents such as silent treatments, withholding of important information and providing a cold shoulder to a follower might enforce the employee to behave in a certain manner leading towards compulsory citizenship behavior.

Indirect EffectsThe indirect effects of the higher-level manager's ethical leadership practices on individual level citizenship behavior can also be study through an intervention of workplace ostracism. However, the existing literature on workplace ostracism has not kept into consideration the impact of hierarchical level ethical leadership on citizenship behavior. Therefore, this study proposes that, as the higher-level managers tend to be the most influential figures within an organizational context so they can determine citizenship behavior of employees by making use of ostracized behavior. As the level of interaction is relatively limited with the higher-level managers so ostracism will have a relatively lesser impact on individual's organizational citizenship behavior. For example, if a departmental head does not reply to your greetings then it might intrigue the employee to have more organizational citizenship behavior in order to impress the departmental head with the voluntarily performed extra role behavior. This might also lead to having lesser possibilities for compulsive citizenship behavior.

Moreover, the indirect effects of lower level manager's ethical leadership practices on individual level citizenship behavior can also have similar repercussions when studied through an intervention of workplace ostracism. Although the lower level managers tend to have relatively lesser influential personalities within an organizational context, so an ostracized behavior of the manager might enforce compulsory citizenship behavior. For example, if a lower level manager is showing cold shoulder to an employee or ignoring him/her then the employee might feel certain external pressure to perform in a desired manner leading towards compulsory citizenship behavior. Therefore, it is deduce that workplace ostracism will also vary according to hierarchical levels of management because of the differing influence, prestige and power of the manager determining citizenship behavior.

\section{Conclusion}

Altruism, civic virtue, conscientiousness, sportsmanship and courtesy are behaviors necessary to study in organizational context in order to highlight the factors that tend to leave a negative or a positive impact on citizenship behavior. To draw attention to this phenomenon, a multi-level model is propose in order to help us develop greater insights.

The present study enriches our understanding of the impact of ethical leadership on citizenship behavior through a mediating impact of workplace ostracism. Ethical leadership and workplace ostracism are two distinct constructs, which are previously consider to influence organizational citizenship behavior (Leung et al., 2011; Yang \& Wei, 2018). In support, social exchange theory and social learning theory provides validation of these constructs in terms of being important predictors of behavior. 
A pivotal construct in our model is workplace ostracism, which has previously obtained very little attention in organizational settings. Rationales are provide regarding the relationship between managerial level ethical leadership and workplace ostracism. In simpler words, as determined from this study, immediate level manager's ostracized behavior tends to leave the greatest impact on individual level citizenship behavior. Furthermore, the ostracized behavior of higher-level managers will have relatively lesser impact on citizenship behavior as although these leaders are influential personalities but they have relatively lesser interactions with the middle level employees prevailing within an organization. Therefore, the roles of distal and proximal leaders are study in determining citizenship behavior.

This research has some theoretical implications contributing to the existing literature. Firstly, the relationship of ethical leadership and individual level citizenship behavior is analyze through a multi-level perspective enhancing the direct, indirect and cascading effects. A multi-level perspective provided a clearer stance regarding the influence of higher level, lower level and immediate level managers in influencing behavior. The study contributes that higher level and immediate level manager's ethical standards will greatly predict the type of citizenship behavior. Secondly, knowing that we know limited about workplace ostracism as being an important determinant of behavior, this research contributes to the theoretical grounds of highlighting the mediating effects of workplace ostracism on citizenship behavior. Workplace ostracism not only mitigates the relationship between ethical leadership and organizational citizenship behavior but also encourages the propensity of the focal employees to perform compulsory citizenship behavior.

In addition to the above-mentioned theoretical implications, this research also provides some useful practical implications as well. It will benefit the human resource managers in identifying the factors affecting citizenship behaviors and can accordingly derive certain strategies for improvements. The human resource management department will analyze even the unethical leadership concerns and measures taken to formalize the ethical standards. The senior managers will be able to determine the behavior of employees to make appropriate predictions regarding their work outcomes. Moreover, the detrimental effects of workplace ostracism identified in this study can encourage a work environment that will emphasize on face-to-face discussions between leaders and followers.

Although the study has achieved some meaningful insights, there are inevitably some shortcomings as well. This theoretical model can be empirically test in order to provide support for the propositions. In addition, the focal employees considered for this model comprised of middle level employees. Therefore, the impact of their immediate manager was propose to be the most significant in influencing behavior. Therefore, some promising future research directions could be extent the domain of focal employees and study the impacts on the behavior of lower level employees of higher-level ethical leaders. In addition, research can be conduct on the cultural diversity, which varies an employee's perception of ethical leaders.

\section{Bibliography}

Ahmad, S. W., \& Khan, T. (2016). Does Motivation Lead to Organizational Citizenship Behavior? "A Theoritical Review. Global Journal of Management and Business Research.

Alkan, S. E., \&Turgut, T. (2015). A research about the relationship of psychological safety and organizational politics perception with compulsory citizenship behavior and the pressures behind compulsory citizenship behavior. Research journal of Business and Management, 2(2), 185-203.

Avolio, B. J. (1999). Full leadership development: Building the vital forces in organizations. Sage.

Bass, B. M., \&Steidlmeier, P. (1999). Ethics, character, and authentic transformational leadership behavior. The leadership quarterly, 10(2), 181-217.

Bolino, M. C., Turnley, W. H., Gilstrap, J. B., \&Suazo, M. M. (2010). Citizenship under pressure: What is a "good soldier" to do? Journal of Organizational Behavior, 31(6), 835-855.

Brandes, P., Dharwadkar, R., \& Wheatley, K. (2004). Social exchanges within organizations and work outcomes: The importance of local and global relationships. Group \& Organization Management, 29(3), 276-301.

Brown, M. E., \& Mitchell, M. S. (2010). Ethical and unethical leadership: Exploring new avenues for future research. Business Ethics Quarterly, 20(4), 583-616.

Brown, M. E., \&Treviño, L. K. (2006). Ethical leadership: A review and future directions. The leadership quarterly, 17(6), 595-616.

Brown, M. E., Treviño, L. K., \& Harrison, D. A. (2005). Ethical leadership: A social learning perspective for construct development and testing. Organizational behavior and human decision processes, 97(2), 117-134.

Chan, S. H. J., \& Lai, H. Y. I. (2017). Understanding the link between communication satisfaction, perceived justice and organizational citizenship behavior. Journal of business research, 70, 214-223. 
Colquitt, J. A. (2001). On the dimensionality of organizational justice: a construct validation of a measure. Journal of applied psychology, 86(3), 386.

Duffy, M. K., Ganster, D. C., \&Pagon, M. (2002). Social undermining in the workplace. Academy of management Journal, 45(2), 331-351.

Ehrhart, M. G., \&Naumann, S. E. (2004). Organizational citizenship behavior in work groups: a group norms approach. Journal of applied psychology, 89(6), 960.

Ferris, D. L., Brown, D. J., Berry, J. W., \&Lian, H. (2008). The development and validation of the Workplace Ostracism Scale. Journal of Applied Psychology, 93(6), 1348.

Fox, S., Spector, P. E., Goh, A., Bruursema, K., \& Kessler, S. R. (2012). The deviant citizen: Measuring potential positive relations between counterproductive work behaviour and organizational citizenship behaviour. Journal of Occupational and Organizational Psychology, 85(1), 199-220.

George, J. M., \& Brief, A. P. (1992). Feeling good-doing good: a conceptual analysis of the mood at workorganizational spontaneity relationship. Psychological bulletin, 112(2), 310.

Gerstner, C. R., \& Day, D. V. (1997). Meta-Analytic review of leader-member exchange theory: Correlates and construct issues. Journal of applied psychology, 82(6), 827.

Hitlan, R. T., Kelly, K. M., Schepman, S., Schneider, K. T., \&Zárate, M. A. (2006). Language exclusion and the consequences of perceived ostracism in the workplace. Group Dynamics: Theory, Research, and Practice, $10(1), 56$.

Konovsky, M. A., \& Organ, D. W. (1996). Dispositional and contextual determinants of organizational citizenship behavior. Journal of organizational behavior, 253-266.

LePine, J. A., Erez, A., \& Johnson, D. E. (2002). The nature and dimensionality of organizational citizenship behavior: a critical review and meta-analysis. Journal of applied psychology, 87(1), 52.

Leung, A. S., Wu, L. Z., Chen, Y. Y., \& Young, M. N. (2011). The impact of workplace ostracism in service organizations. International Journal of Hospitality Management, 30(4), 836-844.

Lim, B. T., \& Loosemore, M. (2017). The effect of inter-organizational justice perceptions on organizational citizenship behaviors in construction projects. International Journal of Project Management, 35(2), 95-106.

Liu, H., \& Xia, H. (2016). Workplace Ostracism: A Review and Directions for Future Research. Journal of Human Resource and Sustainability Studies, 4(03), 197.

Lowe, K. B., Kroeck, K. G., \&Sivasubramaniam, N. (1996). Effectiveness correlates of transformational and transactional leadership: A meta-analytic review of the MLQ literature. The leadership quarterly, 7(3), 385425 .

Luthans, F., \& Youssef, C. M. (2007). Emerging positive organizational behavior. Journal of management, 33(3), 321-349.

Mayer, D. M., Aquino, K., Greenbaum, R. L., \&Kuenzi, M. (2012). Who displays ethical leadership, and why does it matter? An examination of antecedents and consequences of ethical leadership. Academy of Management Journal, 55(1), 151-171.

Mayer, D. M., Kuenzi, M., Greenbaum, R., Bardes, M., \& Salvador, R. B. (2009). How low does ethical leadership flow? Test of a trickle-down model. Organizational behavior and human decision processes, 108(1), 1-13.

McAllister, D. J. (1995). Affect-and cognition-based trust as foundations for interpersonal cooperation in organizations. Academy of management journal, 38(1), 24-59.

Organ, D. W. (1988). A restatement of the satisfaction-performance hypothesis. Journal of management, 14(4), 547557.

Palanski, M. E., \&Yammarino, F. J. (2009). Integrity and leadership: A multi-level conceptual framework. The Leadership Quarterly, 20(3), 405-420.

Podsakoff, N. P., Whiting, S. W., Podsakoff, P. M., \& Blume, B. D. (2009). Individual-and organizational-level consequences of organizational citizenship behaviors: A meta-analysis. Journal of applied Psychology, 94(1), 122.

Podsakoff, P. M., MacKenzie, S. B., Paine, J. B., \&Bachrach, D. G. (2000). Organizational citizenship behaviors: A critical review of the theoretical and empirical literature and suggestions for future research. Journal of management, 26(3), 513-563.

Rhoades, L., \&Eisenberger, R. (2002). Perceived organizational support: a review of the literature. Journal of applied psychology, 87(4), 698.

Schaubroeck, J. M., Hannah, S. T., Avolio, B. J., Kozlowski, S. W., Lord, R. G., Treviño, L. K., ... \& Peng, A. C. (2012). Embedding ethical leadership within and across organization levels. Academy of Management Journal, 55(5), 1053-1078. 
Shin, Y., Sung, S. Y., Choi, J. N., \& Kim, M. S. (2015). Top management ethical leadership and firm performance: Mediating role of ethical and procedural justice climate. Journal of Business Ethics, 129(1), 43-57.

Tepper, B. J. (2000). Consequences of abusive supervision. Academy of management journal, 43(2), 178-190.

Tepper, B. J., Moss, S. E., \& Duffy, M. K. (2011). Predictors of abusive supervision: Supervisor perceptions of deeplevel dissimilarity, relationship conflict, and subordinate performance. Academy of Management Journal, 54(2), 279-294.

Treviño, L. K., \& Brown, M. E. (2005). The role of leaders in influencing unethical behavior in the workplace. Managing organizational deviance, 69-87.

Van Dyne, L., Graham, J. W., \&Dienesch, R. M. (1994). Organizational citizenship behavior: Construct redefinition, measurement, and validation. Academy of management Journal, 37(4), 765-802.

Vigoda-Gadot, E. (2007). Redrawing the boundaries of OCB? An empirical examination of compulsory extra-role behavior in the workplace. Journal of Business and Psychology, 21(3), 377-405.

Vigoda-Gadot, E. R. A. N. (2006). Compulsory citizenship behavior: Theorizing some dark sides of the good soldier syndrome in organizations. Journal for the Theory of Social Behaviour, 36(1), 77-93.

Walumbwa, F. O., \&Schaubroeck, J. (2009). Leader personality traits and employee voice behavior: mediating roles of ethical leadership and work group psychological safety. Journal of applied psychology, 94(5), 1275.

Walumbwa, F. O., Mayer, D. M., Wang, P., Wang, H., Workman, K., \& Christensen, A. L. (2011). Linking ethical leadership to employee performance: The roles of leader-member exchange, self-efficacy, and organizational identification. Organizational Behavior and Human Decision Processes, 115(2), 204-213.

Yam, Kai Chi, Anthony C. Klotz, Wei He, and Scott J. Reynolds. "From good soldiers to psychologically entitled: Examining when and why citizenship behavior leads to deviance." Academy of Management Journal 60, no. 1 (2017): 373-396.

Yang, Q., \& Wei, H. (2018). The impact of ethical leadership on organizational citizenship behavior: The moderating role of workplace ostracism. Leadership \& Organization Development Journal, 39(1), 100-113.

Yildiz, H., \&Yildiz, B. (2016). The effects of ethical leadership, servant leadership and leader-member exchange on compulsory citizenship behaviors. International Business Research, 9(2), 19.

Zhao, H., Peng, Z., \& Chen, H. K. (2014). Compulsory citizenship behavior and organizational citizenship behavior: The role of organizational identification and perceived interactional justice. The Journal of psychology, 148(2), 177-196.

\section{APPENDIX A Constitutive Definitions}

Organizational Citizenship Behavior

Compulsory Citizenship Behavior

Altruism

Civic Virtue

Conscientiousness

Sportsmanship Courtesy

Ethical Leadership

Idealized Influence

Interactional Fairness

Affective Trust

Abusive Supervision

Workplace Ostracism

Social Undermining

Interpersonal Justice

Perceived Organizational Support
It is the individual behavior that is discretionary, not directly or explicitly recognized by the formal reward system and that in the aggregate promotes the effective functioning of the organization (Organ 1988)

It is an involuntary behavior, which is not a result of the self-driven good will of the individual himself (VigodaGadot, 2007)

It is defined as the behaviors that help other members (Organ, 1988)

A behavior that entails political participation (Organ, 1988).

A behavior that goes beyond those expected by specific role requirements (Organ, 1988)

A behavior that avoids complaining or aggravating unpleasant situations (Organ, 1988).

A behavior that prevents problems from occurring (Organ, 1988).

It is the demonstration of normatively appropriate conduct through personal actions and interpersonal relationships (Brown, Trevino \& Harrison 2005).

It is the influence of the leaders to become a role model for followers to emulate by delivering high standards of ethical and moral conduct (Avolio, 1999).

It is the supervisory leadership focus of treating employees with dignity, respect and fairness of decisions (Avolio, 1999).

It is the trust based upon caring and concern of the supervisor (Brown, Trevino \& Harrison 2005).

A sustained display of hostile verbal and non-verbal behaviors (Tepper, 2000).

An individual's perception of being ignore or excluded at work (Ferris et al. 2008)

Behavior intended to hinder, over time, the ability to establish and maintain positive interpersonal relationships, work-related success and favorable reputation (Duffy et al. 2002).

The extent to which an individual is treated with respect and propriety (Colquitt, 2001)

An employee's belief's regarding the extent to which the organization cares about the employee's well-being (Rhoades \&Eisenberger, 2002)

The quality of the exchange relationship between a leader and his/her follower (Gerstner \& Day, 1997) 
APPENDIX B

Measures and Theoretical Justifications

\begin{tabular}{l} 
Measures \\
\hline Measures of Citizenship Behavior: \\
Altruism will influence the helpful behavior of an employee, which will determine \\
the citizenship behavior.
\end{tabular}

the citizenship behavior.

Civic virtue will influence political participation of an employee, which will determine the citizenship behavior.

Conscientiousness will influence the role expectations of an employee, which will determine the citizenship behavior.

Sportsmanship will influence the complaining behavior of an employee, which will determine the citizenship behavior.

Courtesy will influence the appreciating behavior of an employee, which will determine the citizenship behavior.

\section{Measures of Ethical Leadership:}

The greater the idealized influence between the supervisor and subordinate, the stronger the ethical leadership prevalent within the organization.

The greater the interactional fairness between the supervisor and subordinate, the stronger the ethical leadership prevalent within the organization.

The greater the affective trust between the supervisor and subordinate, the stronger the ethical leadership prevalent within the organization.

The lesser the abusive supervision between the supervisor and subordinate, the stronger the ethical leadership prevalent within the organization.

\section{Measures of Workplace Ostracism:}

The greater social undermining between the supervisor and subordinate, the stronger workplace ostracism prevalent within the organization.

The lesser interpersonal justice existing between the supervisor and subordinate, the stronger workplace ostracism prevalent within the organization.

The lesser perceived organizational support existing between the supervisor and subordinate, the stronger workplace ostracism prevalent within the organization.

The lesser leader-member exchange existing between the supervisor and subordinate, the stronger workplace ostracism prevalent within the organization
$\mathrm{AT} \rightarrow \mathrm{CB}$

$\mathrm{CV} \rightarrow \mathrm{CB}$

$\mathrm{CS} \rightarrow \mathrm{CB}$

$\mathrm{SP} \rightarrow \mathrm{CB}$

$\mathrm{CT} \rightarrow \mathrm{CB}$

$\mathrm{AT} \rightarrow \mathrm{EL}$

$\mathrm{AS} \rightarrow \mathrm{EL}$

$\mathrm{SU} \rightarrow \mathrm{WO}$

$\mathrm{IJ} \rightarrow \mathrm{WO}$

$\mathrm{POS} \rightarrow \mathrm{WO}$

$\mathrm{LMX} \rightarrow \mathrm{WO}$
(Lim \& Loosemore, 2017)

(Kanovsky\& Organ

1996)

$+$

(Lim \& Loosemore, 2017)

(Kanovsky\& Organ 1996)

$+$

(Lim \& Loosemore, 2017)

(Kanovsky\& Organ 1996)

$+\quad$ (Lim \& Loosemore, 2017)

(Kanovsky\& Organ 1996)

$+$

(Lim \& Loosemore, 2017)

(Kanovsky\& Organ 1996)

(Bass \&Steidlmeier 1999)

(Brown, Trevino \&

Harrison 2005)

(Bass \&Avolio, 2000)

(Brown, Trevino \& Harrison 2005)

$+$ (McAllister, 1995)

(Tepper, 2000)

(Tepper, Moss \& Duffy, 2011)

(Duffy et al. 2002) (Ferris et al. 2008)

(Duffy et al. 2002)

(Ferris et al. 2008)

(Duffy et al. 2002)

(Ferris et al. 2008 
APPENDIIX C

Theoretical Propositions

\section{Propositions}

Higher-level manager's ethical leadership practices will directly leave an impact on the individual level citizenship behavior of employees.

The greater ethical leadership practices of higher-level managers will enable them to avoid ostracized behavior leading towards organizational citizenship of employees.

The lesser ethical leadership practices of higher-level managers will enable them to perform ostracized behavior leading towards compulsory citizenship behavior of employees.

Lower level manager's ethical leadership practices will directly leave an indifferent impact on the individual level citizenship behavior.

The greater ethical leadership practices of lower level managers will enable them to avoid ostracized behavior leaving no major influence on organizational citizenship behavior of employees.

The lesser ethical leadership practices of lower level managers will enable them to perform ostracized behavior leaving no major influence on compulsory citizenship behavior of employees.

Middle level manager's (immediate managers) ethical leadership practices will leave impact on the individual level citizenship behavior.

The greater ethical leadership practices of immediate level managers will enable them to avoid ostracized behavior leading towards organizational citizenship behavior of employees.

The lesser ethical leadership practices of immediate level managers will enable them to perform ostracized behavior leading towards compulsory citizenship behavior 